\title{
READERS
Insight
}

Journal of Management Info (JMI)

ISSN:2313-3376

www.readersinsight.net/jmi

Mit

\section{The effect of organizational culture on knowledge sharing among academic staff holding an administrative position in university}

\author{
Mohammad Mahmoud $^{1 *}$, Amran Rasli $^{2}$, Mohd Fauzi bin Othman ${ }^{3}$, Bawer Marwan Abdulahad $^{4}$ \\ ${ }^{1,2,3,4}$ Faculty of Management, Universiti Teknologi Malaysia, Johor, Malaysia
}

* Corresponding author: mohammad.lawyer@ymail.com

\begin{abstract}
Knowledge sharing is the primary source of gaining competitive advantage and achieving long term success. Knowledge sharing is affected by many factors and the foremost of them is the culture of an organization. Organizational culture will help in developing the knowledge sharing practices among the members of an organization and achieve organizational objectives. The aim of the present study firstly, is to find out how the culture affects knowledge sharing in UTM (Universiti Teknologi Malaysia) and which of the cultural factors are more prevalent in developing knowledge sharing practices; secondly, to determine the level of knowledge sharing among the academic staff holding administrative positions in various faculties and departments of the university. Using quantitative approach, data was collected through survey questionnaire from a sample of 132 respondents. The analysis was carried out using descriptive and inferential statistics. Three of the dimensions of OC, workgroup support, information technology, and social interaction are found to be most significant in UTM, while reward system is found to be insignificant. Knowledge sharing is found to be high among academic staff holding administrative posts. The study concludes that organizational culture factors, workgroup support, information technology and social interaction are the most important factors that are helping in enhancing knowledge sharing in UTM. Finally, some recommendations related to the future studies are also included like investigating all levels and incorporating both administrative and academic staff, comparison with other public sector universities and between public and private sector universities.
\end{abstract}

\section{ARTICLE INFORMATION}

$\begin{array}{ll}\text { Received: } & 25 \text { March } 2014 \\ \text { Revised: } & 25 \text { July } 2014 \\ \text { Accepted: } & 25 \text { August } 2014\end{array}$

DOI:

http://dx.doi.org//10.31580/jmi.v3i1.13

\section{Introduction}

In many organizations, knowledge is considered or known as one of the primary sources of competitive advantage and it plays a great role in the long term sustainability and success of any organization. Therefore, it is an essential for organizations to manage intellectual capital in order to promote the success of their business (Walczak, 2005). It is essential to gain competitive advantage yet it is inadequate for organizations to rely on staffing alone which focuses on selecting employees who have specific knowledge, skills, abilities and competencies or helping employees acquire them (Petrides, 2004). This is what obliges the researchers to confirm that organizational culture is the main factor affecting knowledge sharing efficiency, within organizations to encourage and support knowledge sharing (Roziana, 2004).

Knowledge sharing is the corner-stone of many organizations' knowledge-management (KM) strategy. Hence the growing significance of knowledge sharing's practices for organizations' competitiveness and market performance. Adequate resources to support knowledge flows and collaboration need to be allocated. Further, the success or failure of a knowledge sharing strategy is dependent on its integration into the goals and strategy of the organization. It is the responsibility of senior management to communicate those goals and strategies to all employees in a transparent fashion to obtain support (Riege, 2005). In the context of higher education institutions, the issue of knowledge sharing is important because knowledge production, distribution and application are ingrained in the university. Though there is no direct way to measure the outcome of knowledge sharing in knowledge institutions, the impact of knowledge sharing could be larger than those created by the business organizations (Cheng et al., 2009). The effective knowledge sharing is achievable through socialization process within supportive organizational culture. However, academic staff's non-supportive beliefs in sharing knowledge in either formal or informal ways can cause knowledge management efforts fail in an organization (Shaari \& Alias, 2007).

The present study is conducted in the context of higher educational institutions in Malaysia. Malaysia is a fast developing country focusing on becoming high income living country by year 2020 . The transformation of modem world business from production based economy to a knowledge based economy has major implications for Malaysia. Malaysia established the Multimedia Super Corridor (MSC) to spearhead the country into the information technology era. The advantage is that it enables Malaysia to realize its dream of becoming a developed nation by the year 2020; and a total structural change of the country's industrialization plan. In fact, through the three institutions in Malaysia (universities, public schools and public or private sector institutions) that are responsible in developing people, universities seemed to be the most important institution that could close the gap between current levels of knowledge and skills and the future level that is required in achieving Vision 2020 (Roziana, 2004). 
In addition, vision 2020, inspired by the former Prime Minister, Tun Dr. Mahathir Mohamad, aims to make Malaysia a developed nation by year 2020. Even more, in September 2002 the Government of Malaysia has launched the K-economy Strategic Master Plan. This plan aims to give Malaysia the competitive advantage needed to compete in today's complex and dynamic environments. The plan asserted the importance of knowledge and suggests a creative plan to increase and promote the numbers of knowledge workers in Malaysia. This plan is most important due to the price of knowledge held in today's world. Meanwhile, knowledge acts as the primary resource of the new economy. As a result, the government tried to be dependent very heavily on Higher Education Organizations (HEO) especially universities. On the other hand, towards achieving the objective of Vision 2020, Malaysian Public Institution of Higher Education has their own role in supporting Vision 2020 by producing knowledgeable manpower or knowledge worker to the country. As other non-profit organizations, Malaysian Public Institution of Higher Education has make steps on the implementation of Knowledge Management in their organization (Sani, 2008).

This study is an attempt to find out the most influencing organizational factors in knowledge sharing in a university context. Al-Alawi et al., (2007) has pointed out that factors such as workgroup support, reward system, social interaction, and technologies, etc, play an important role in defining the relationships between staff and also providing opportunities to jump barriers in sharing knowledge.

\section{Literature review}

\section{Knowledge}

Knowledge is considered to be the power house of the new era of knowledge based economy (Sohail \& Daud, 2009). Also, Davenport and Prusak (1998) defined knowledge as a fluid mix of framed experience, values, contextual information, and expert insight that provide a framework for evaluating and incorporating new experience and information. The minds of people are embodied with great knowledge, while a significant amount of it is stored in organizational artifacts like documents or repositories. Nonaka (1994) and Polanyi (1966) classified knowledge into tacit and explicit knowledge. Tacit knowledge includes insights, intuitions, and hunches that are hard to express and formalize, and therefore, difficult to share. Hence, tacit knowledge is likely to be personal and individual based experience. Unlike Tacit knowledge, explicit knowledge is knowledge that has been expressed into words and numbers and can thus be formally and systematically shared in the form of data, specifications, manuals, drawings, audio and video tapes, etc. The development of tacit knowledge through experience takes time and requires considerable investment (McKenzie \& van Winkelen, 2004).

\section{Knowledge management}

Generally, KM focuses on facilitating and managing knowledgerelated activities, such as creation, capture, transformation and use of knowledge (Lin, 2007). As defined by Gurteen (1998) KM is an emerging set of organizational design and operational principles, processes, organizational structures, application and technologies that facilitate knowledge workers in leveraging their creativity and capability to deliver business value. Additionally, to make the organization successful, it is very important to manage their knowledge well. In today's' knowledge explosion era, organizations tend to face lots of difficulty to survive without proper knowledge management initiatives.

In review of previous researches, many definitions are made to understand knowledge management; for example, Botkin (1999) defined knowledge management as the process of capturing, sharing and leveraging the expertise of a company in order to improve the decision making so as to achieve organizational goals. Another definition by Nikolas (2004), states that knowledge management is an efficient process for creating, acquiring and disseminating, leveraging and use of knowledge, in order to maintain competitive advantage and achieve organizational objectives.
Sharing information and knowledge among employees is an essential element in the process of knowledge management. The knowledge management processes include discovery, capture, sharing and application in which there are seven sub processes. Of the seven, Nonaka (1994) identified four ways of managing knowledge: socialization, externalization, internalization and combination. The remaining three sub processes (exchange, direction and routines) were proposed by Grant (1996). Tiwana (2003) classified knowledge management in three different processes, namely: knowledge acquisition, knowledge sharing and knowledge utilization. From the above processes, it is believed that knowledge sharing is one of the most important processes for KM.

\section{Knowledge sharing}

Knowledge sharing is the basic means through which employees can contribute to knowledge application, innovation and most importantly the competitive advantage of the organization (Jackson et al., 2006). Sharratt and Usoro (2003) defines sharing as a process whereby a resource is given by one party and received by another, while Fernandez et al., (2004), defines knowledge sharing as a process through which explicit or tacit knowledge is communicated to other individuals. Knowledge sharing comprise of a set of shared understanding, which is related to providing employees with access to relevant information through knowledge networks within organizations (Hoegl et al, 2003). Hence, knowledge sharing is considered as central to the success of all knowledge management strategies in an organization (Chaudhry, 2005).

Findings from many researches indicate that knowledge sharing depends more on the characteristics of an individual such as experience, values, motivation and beliefs. According to Islam et al., (2011), individual motivators may enable knowledge sharing, and willingness of employees, as they are motivated to share when they realize the worth of helping others. However, organizational culture is normally required to capture the benefits of knowledge efficiently. There are different aspects of organizational culture, such as reward systems, top management support and open leadership etc. Finally, the technology dimension enables knowledge sharing through effective usage of ICT ease to integrate, codify and disseminate organizational knowledge.

Knowledge management has been acknowledged as a vital element for recent businesses organization. While individuals within the organizations might recognize the importance of knowledge management for the success of their day to day business functions. According to these perspectives, individuals share knowledge because this process could bring them certain benefit in the future, or improve their perception of self-efficacy; also people may proactively share knowledge or new ideas with others in the hope of seeking feedback and comments, or get more thorough understanding of the knowledge (Zhang \& Jian, 2012).

\section{Organizational culture}

Most researchers agree that organizational culture is a common system of values and beliefs that leads to the formulation and composition of personal patterns in organizational members through knowledge and concepts publishing (Lie \& Fang, 2010).

Culture can distinguish between the three components; First is component of moral and includes values, ethics and beliefs the ideas that espoused by the individual. Second is material component and includes all of the produce or deal with members of the community of machinery, equipment and facilities available and third is behavioral component and appears in the customs and traditions followed by the members of the community in addition to the arts, literature and practices scientific conditions and various events, indeed culture is a mixture of these three components in varying proportions (Bush \& Middlewood, 2005). Additionally the culture concept stems from human term itself, which means through research and exploration and all the values that lend themselves to the existence of human and focuses on knowledge that is what is needed in accordance with the environment conditions and its society (Schein, 2006). Moreover culture means understanding the nature of community issues and 
taking care of a renewed process which never end. Clearly, culture is the environment, which is where the individual formalize character and personality to gain a degree of knowledge and science such as creativity and the technical and aesthetic innovation, as a pattern of expression and behavior for a particular community and other concepts (Ling, 2011).

According to Al-Alawi et al (2007) economic institutions seek to strengthen their competitiveness and ensure their existence and continuity by resolving to prevailing organizational culture which needs to be developed to keep pace with global, economic, technical, political, and social changes. Organizational culture is intended as a set of values, traditions and trends, assumptions, and norms that prevail in the organization and reflect on the employee's behavior passed down through the generation, which serves as the basis for formulating of an individual's personality and interests (Hartnell et al., 2011). According to Liu and Fang (2010) organizational cultures contribute to the formulation and composition of personal patterns to organization individuals through knowledge and concepts publishing, that lead to determine the information and environment, including enhancing social interaction among members through promotion of social relationships, because knowledge culture contribute to avoiding confusion in relationships and organizes it, to enrich social experiments. In fact, the success of any organization is linked to an organization culture in which people are encouraged to work together and share resources as needed (Ryan et al., 2010).

\section{Relationship between organizational culture and knowledge sharing}

According to Jashapara (2004) the failure of knowledge management systems is often a result of cultural factors than technological oversights. He defined culture as a deep structure of organizations, which is embedded in the values, beliefs and assumptions held by members of the organization. To create and maintain knowledge sharing culture is one of the most challenging jobs for modern managers. If there is a strong knowledge sharing culture, knowledge can be shared easily among employees through social and electronic networks.

Campbell (2009) supports that organizational culture is related to knowledge sharing culture, and organizational factors such as corporate vision, mission statements, rewards and information services should make possible a sharing culture. The extent to which each organizational factor is documented and shared determines the suitability of the common culture for knowledge sharing which includes the distribution of reliable working procedures, job knowledge as well as project deliverables. Strategic and operational objectives, human resource systems and information databases influence the way people work and therefore, describes the behavior of an organization. In addition a strong knowledge sharing culture creates an informative organization that can react fast to key issues (Moradi et al., 2012).

One importance of organizational culture is to facilitate effective knowledge sharing. Firstly, in order to build a knowledge sharing culture, the connection between sharing knowledge and practical organizational goals, problems or results should be made visible in the organization. Secondly, priority should be given in matching the overall style of organization rather than to directly copy the practices developed by other organizations. Thirdly, the sharing of knowledge must be linked to core values so as to encourage the consistency of knowledge sharing in an organization with peer's expectations and manager's consideration. Fourthly, to build a sharing culture, organizations have to develop the existing networks as human networks are one of the key factors for sharing knowledge (Islam et al., 2011).

Finally, the support of people in organization who already share ideas and insight are important as well. This is simply because, through their influence and encouragement, the sharing of knowledge can be built into routine performance appraisal (Rahgozar et al., 2012). In order to facilitate knowledge sharing, the most important thing is to encourage the factors associated with knowledge sharing. This can be done through focusing on reducing the barriers on both the individual level and organizational level. To do this, the management of the organization can promote a better culture that enhances knowledge sharing (Lin, 2007).

\section{Knowledge sharing in academic setting}

Although detailed studies of the relationship between knowledge sharing and organizational culture are still limited especially in academic contexts, however there are few studies that relate organizational factors with knowledge sharing. For example, Rozianna (2004) carried out a study to understand the practices of knowledge sharing in public sector universities in Malaysia and found that organizational culture and employee attitude seem to be the most influencing factor of Knowledge Sharing in the organizations. Jain et al (2007) conducted a study which focused on Knowledge Sharing activities among Academic Staff in Business Schools in Klang Valley, Malaysia and found out that the academic staff felt strongly about the significance of knowledge sharing in an academic environment. Also, in the study several barriers to KS were identified such as lack of reward and recognition, lack of time and lack of formal and informal activities to cultivate knowledge sharing. In a study conducted by Roziana, (2013) on the issues and challenge that academia face with in knowledge sharing in academic setting in Malaysia, shows that the main issues in knowledge sharing practices are university structure and designation and title. Thus academia awareness in sharing knowledge is also influenced by culture. Furthermore this investigation highlighted that the concept of reciprocal relationship of sharing knowledge may hinder knowledge sharing awareness among academia.

\section{Research framework and hypotheses}

Based on the previous researches on organizational culture and knowledge sharing following framework is proposed for the present study. The organizational culture factors are workgroup support, reward system, social interaction, and information technology; while for knowledge sharing Figure 1.

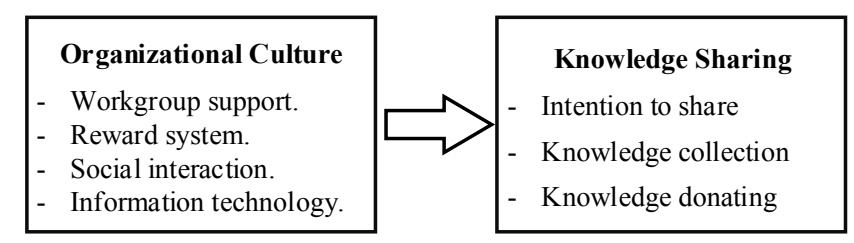

Fig. 1. Framework

The subsequent hypotheses developed for the study and based on the study framework are:

H1: Organizational culture would significantly influence knowledge sharing in the organization

H1a: Workgroup support will significantly influence knowledge sharing in the organizational

H1b: Reward System will significantly influence knowledge sharing in the organizational

H1c: Social Interaction will significantly influence knowledge sharing in the organizational

H1d: Information technology will significantly influence knowledge sharing in the organizational

\section{Methodology}

The study was conducted among academic staffs in Universiti Teknologi Malaysia. The sample has been drawn from the academic staff especially holding administrative positions in the university, to investigate the role of organizational culture in knowledge sharing. The total population of academic staff holding administrative position in the university was 195 . The sample of 132 respondents was drawn from Krejcie and Morgan (1970) sample size table using random sampling technique. The respondents were chosen specifically 
starting with top management from dean, deputy dean, (academic and development), head of department, IT manager, academic managers and coordinators (postgraduate and undergraduate). This research is focused on the middle and upper academic staff positions in the faculties. Based on the organizational chart provided by faculty administrative office (Academic Office), and the actual list in every faculty web site the population for this study is a total of one hundred and ninety five (195) academic staffs that hold administrative posts in all the faculties of the university. The population of this study is helpful in understanding the effectiveness of organizational culture on knowledge sharing process among academic staffs that hold administrative posts, where they are involved in management processes to indicate their contributions at the same time, to the process of sharing knowledge with regards to both their academic and administrative jobs.

A survey questionnaire was designed with the intent to provide data about the effectiveness of organizational culture on knowledge sharing among academic staffs that hold administrative posts in different faculties' of the university. To ensure the respondents are guided, questions included in the questionnaire were well structured and clear. The researcher attempted to make the questions very simple and understandable to make sure all the respondents were clear about the questions.

The questionnaire consisted of three sections. The first section captured the demographic profile of the respondents. The second section consisted of items related to organizational culture dimensions, while section three consisted of items concerning knowledge sharing. The section two and three items were scaled on a 5-point Likert scale where "5 - Strongly Agree" and "1 - Strongly Disagree". The items for workgroup support were adapted from the study of Sveiby \& Simons (2002); Reward system items were adapted from Lin (2007); Social interaction (Kim \& Lee, 2006); Information technology (Zhang, et al, 2006) and Knowledge sharing (Lin, 2007). The reliability of the questionnaire was determined using Cronbach alpha. The alpha values for all the factors were found to be between .75 and .92 , indicating that the questionnaire was reliable enough for further statistical analysis.

\section{Analysis and discussion}

The Pearson correlation analysis of the factors of organizational culture and knowledge sharing indicate that knowledge sharing has positive and significant relationship with three dimensions of organizational culture that is workgroup support, social interaction and information technology. However, the reward system is found to have insignificant relationship with the knowledge sharing. The results are shown in Table 1.

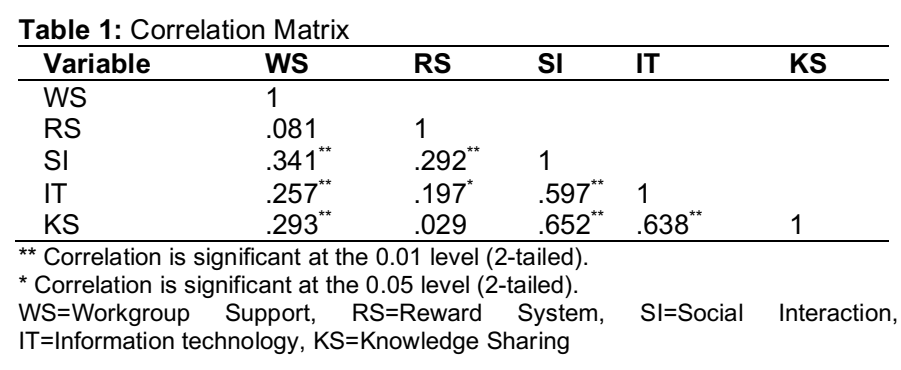

The regression analysis using both simple and multiple simultaneous regressions was applied to find out the influence of organizational culture and its factors on knowledge sharing in the organization. The results of regression analysis are shown in Table 2.

The results of regression indicate that organizational culture as a composite variable is having a statistical significant influence on knowledge sharing within organization. The results of multiple regressions for factors of organizational culture indicate that out of fur factors only three factors - workgroup support, social interaction and information technology are having a statistically significant influence on knowledge sharing in the organization.
The results of the study indicate that organizational culture is one of the core antecedents of knowledge sharing in the organization The organizational culture shapes the individual behavior that is stimulus for knowledge sharing. The knowledge sharing is an activity that is concerned with active collaboration among members of organization and these members must have a shared understanding. Jashapara (2004) is also of the opinion that failure of knowledge management systems is often a result of cultural factors than technological oversights. Knowledge sharing depends on human resources of an organization whose support is necessary for effective sharing of knowledge among colleagues. For this purpose, the organizational policies and culture is the most important element to influence the members of the organization to share their experiences and values (Lin, 2007; Rahgozar et al. 2012; Islam et al, 2011).

Table 2: Regression Analysis

\begin{tabular}{llll}
\hline Model 1 & $\boldsymbol{\beta}$ & $\mathbf{p}$ & Hypothesis \\
\hline Organizational Culture & .462 & .000 & Supported \\
R.493 & & & \\
$\mathrm{R}^{2} .243$ & & & \\
$F$ 41.804 $(p<0.01)$ & & & \\
\hline Model 2 & $\boldsymbol{\beta}$ & $\mathbf{p}$ & Hypothesis \\
\hline Workgroup Support & .241 & .000 & Supported \\
Reward System & .027 & .671 & Not Supported \\
Social Interaction & .335 & .000 & Supported \\
Information Technology & .320 & .000 & Supported \\
\hline R .746 & & & \\
$R^{2} .556$ & & & \\
$F$ 39.757 (p<0.01) & & & \\
Durbin-Watson 1.918 & & & \\
\hline
\end{tabular}

Knowledge sharing among the group members is essential for group tasks. Zárraga and Saá-Pérez (2006) have highlighted the importance of trust among team members for mutual benefit and growth. This trust is developed if organizations provide a conducive environment to members for sharing of experiences and knowledge among group members. The culture of teamwork is needed simply because KS needs interaction to enable the sharing of ideas and knowledge. In addition, the culture of teamwork will also motivate employees to assist each other in completing their task (Ryan et al., 2010). Wickramasinghe and Widyaratne (2012) argue that team building is important in providing skills and techniques of effective cooperation and collaboration in which group members are free to share their knowledge among each other through social bookmarking and brainstorming and collective problem solving, which has had important positive impact on knowledge sharing in comparison to other factors. The present study results also reveal and significant impact of workgroup support towards knowledge sharing in the UTM. Bechina and Bommen (2006) opines that people share their knowledge without realization and mostly during social interaction. In a positive socially conducive organizational environment, employees interact freely and frequently to share knowledge. Furthermore, creating opportunities of social interaction help in building trust among employees and overcoming the knowledge sharing obstacles (Bechina \& Bommen, 2005; Iqbal, et al 2011). Research stresses that social interaction is a core feature of stimulating organizational knowledge sharing (Noorderhaven \& Harzing, 2009). The results of the present study also reveal that knowledge sharing is influenced by the social interaction of the members of the academic staff holding administrative positions in the UTM, who can access and share the knowledge for individual member growth and development within the university.

Technology is one of the common mean used in today's organizations to enable knowledge sharing. The growth of information technology has helped organizations to acquire and share knowledge with their members and has become one of the most critical factors in successful knowledge sharing (Supar, 2012; Davison, et al, 2013). Information technology as a mechanism has helped the societies to become knowledge societies by distributing and sharing information (Kbar, 2010). Without any doubt, there are more likely chances of sharing if an organization is highly technologically enhanced in terms of 
knowledge sharing. This can only be done through focusing on employees" awareness of technological improvements (Casimir et al., 2012). The results of the present study also highlight that the members of the university are well aware of the advantages of the advanced technologies and use them effectively for sharing their knowledge with colleagues and other members of the university.

\section{Conclusion}

In conclusion, the study revealed that Knowledge is the primary source of gaining competitive advantage and long term success. Organizations attempts to acquire skilled human resources to benefit from their expertise and knowledge. In doing so they develop an organizational culture that is best suited for knowledge sharing as it enhances efficiency and achieving organizational objectives. With the advancements in the technology, it has become easier to acquire and distribute knowledge, yet there is still resistance to sharing of personal experiences and knowledge by the organizational members. This can be overcome with the right kind of organizational environment and policies and practices. The present study is an attempt to highlight the role of organizational culture in knowledge sharing in a university context. The results of the study are encouraging from organizational perspective as they show that university academic staff members holding administrative posts are very much practicing knowledge sharing at their levels. The results reveal that university has an environment where members interact socially, receive group support and frequently use information technology for sharing their personal experiences and knowledge with other members at their levels. However, the reward system that should motivate further knowledge sharing is a missing element in the university. The previous studies have highlighted the role reward practices play in developing and enhancing the knowledge sharing in the organization, yet the present study did not find any influence of reward practices on knowledge sharing. The reward policies should be adopted that would not only motivate but compel the academic staff at all tiers to engage in knowledge sharing practices and help other members in their growth and development. This would not help the university alone, but would also help its members grow in terms of knowledge and experience.

The study is limited mainly because of its sample size and also one organization was chosen to be part of this study. The future research should include other universities and a comparative study may yield different results. Furthermore, future research should include other tiers of employees as well, as the present study only took academic staff holding administrative position in the university. Including other faculty members as well as administrative staff members may change the results of the study. Knowledge sharing is greatly affected by culture prevalent in the organization. The present study looked at four dimensions of organizational culture. It is suggested that further cultural factors like human resource practices, organizational structure, management style etc might also be considered for future research. Finally to gain useful and in-depth knowledge on the variables of the study a mix method approach may also be used.

\section{References}

Al-Alawi, A. I., N. Y. Al-Marzooqi and Y. F. Mohammed (2007). Organizational culture and knowledge sharing: critical success factors. Journal of knowledge management 11(2): 22-42.

Chaudhry, A. (2005). Knowledge Sharing Practices in Asian Institutions: A multi-Cultural Perspective from Singapore. World Library and Information Conference and Council: Libraries-a voyage of discoveries. Oslo, Norway.

Cheng, M.-Y., J. S.-Y. Ho and P. M. Lau (2009). Knowledge sharing in academic institutions: a study of Multimedia University Malaysia. Electronic Journal of Knowledge Management 7(3): 313-324.

Islam, Z., I. Hasan, S. Ahmed and S. Ahmed (2011). Organizational culture and knowledge sharing: Empirical evidence from service organizations. African Journal of Business Management 5(14): 5900-5909.

Jashapara, A. (2004). Knowledge management: An integrated approach. Harlow, England, Pearson Education.

Krejcie, R. V. and D. W. Morgan (1970). Determining sample size for research activities. Educational and psychological measurement 30(3): 607-610.

Lin, H.-F. (2007). Knowledge sharing and firm innovation capability: an empirical study. International Journal of Manpower 28(3/4): 315-332.

Mohd Ghazali, M., M. Nor Azirawani, K. Norfaryanti and M. Mar Idawati (2007). The application of knowledge management in enhancing the performance of Malaysian universities. Electronic Journal of Knowledge Management 5(3): 301-312.

Rahgozar, H., F. Afshangian and K. z. ehteshami (2012). The Relationship between Organizational Culture and Knowledge Management (A Case Study at the University of Shiraz). Journal of Basic and Applied Scientific Research 2(4): 3198-3207.

Riege, A. (2005). Three-dozen knowledge-sharing barriers managers must consider. Journal of knowledge management 9(3): 18-35.

Roziana, S. (2004). A Practice Of Knowledge Sharing : A Case Study In A Public Service Organization. Jurnal Kemanusiaan Bil.3(Jun): 6.

Roziana, S., A. R and A. R. Hamidah (2013a). What Deter Academia to Share Knowledge within Research-Based University Status. World Academy of Science, Engineering and Technology (73): 4.

Roziana, S., A. R and M. Y. R. (2013b). The Organizational Issues of Knowledge Sharing among Academic Staffs in the Malaysian Public Universities. International Journal of Knowledge, Culture and Change Management 10(6): 133-148.

Sani, M. A. M. (2008). Mahathir Mohamad as a cultural relativist: Mahathirism on human rights. 17th Biennial Conference of the Asian Studies Association of Australia, Melbourne.

Shaari, R. and R. A. Alias (2007). Human resource development (HRD) strategies for knowledge sharing in a higher learning institution. Jurnal Teknologi Maklumat 19(2): 57-66.

Sveiby, K.-E. and R. Simons (2002). Collaborative climate and effectiveness of knowledge work-an empirical study. Journal of Knowledge Management 6(5): 420-433.

Walczak, S. (2005). Organizational knowledge management structure. Learning Organization, The 12(4): 330-339. 